contemplated. In miliary renal tuberculosis secondary to lesions in other organs there may be only slight disturbance of function, the secondary urinary troubles being marked by the symptoms of the primary lesions. Sometimes, however, incontinence of urine may demand attention and on examination the condition of the urinary organs may be ascertained.

In chronic nephritis and in tuberculous pyelitis the symptoms are generally well marked and differ materially according to the course of events as regulated by the channel along which infection has taken place. As already indicated, in the descending variety the kidney parenchyma is first involved, and the renal trouble, although it may be primary, is generally secondary to some easily recognised tuberculous lesion elsewhere. There is not usually much increase in the size of the organ to begin with, but sooner or later the lower urinary tract becomes involved in a way and with a degree of certainty not seen in other inflammatory diseases. When a mixed infection has taken place and tuberculous abscesses have formed and ruptured into the pelvis pyuria becomes constant, except when the flow from the ureter is retarded by an obstruction, which, however, is usually temporary. At times, therefore, the urine may be almost clear, while at others it is loaded with pus and tuberculous débris. In the ascending form of tuberculous disease vesical symptoms appear early in the course of the disease and are often associated with evidence of tuberculous lesions in the prostate, \&c. The ureter becomes involved before the kidney, hence symptoms arising from obstruction, such as renal colic, transitory pyonephrosis, or increase in the size of the kidney from the dilatation of its pelvis, are observed early in the course of the disease.

(To be continued.)

\section{ON THE RELATION OF BLOOD TO LYMPHATIC VESSELS.}

BY CECIL H. LEAE, M.A., M.B. OANTAB., F.R.C.S. ENG., ASSISTANT SURGEON TO THE GORDON AND CANCER HOSPITALS; LATE ASSISTANT DEMONSTRATOR OF ANATOMY AT THE LONDON HOSPITAL.

IN THE LANCET of June 18th, 1898 (p. 1680), in an article entitled "A Method of Injecting the Lymphatic Vessels," I described a communication which I had observed in the inguinal region of the human subject between a lymphatic vessel on the one hand and a vein on the other. Since that time I have made dissections in the thoracic region in three subjects to determine whether this communication was at all constant and in all these instances have I found it to exist. The following illustrations are drawn from dissections made in these subjects which were hardened by formalin. In Fig. 1 the thoracic duct is double. One of the lower left intercostal veins is seen to terminate not only into the vena azygos minor, but to be connected by a small communicating branch with the left half of the double thoracic duct. In Fig. 4 a large lymphatic trunk is found to terminate directly into the vena azygos major and in the same figure an intercostal lymphatic vessel is seen to terminate in the lowest intercostal vein of the right side. These and other directions show that in the thorax the communication between these two sets of ressels is of no uncommon occurrence and $\mathrm{I}$ am inclined to regard it as a normal ore. It is frequently found that some of the intercostal lymphatics pour their contents into some of the intercostal veins or into one or both of the azygos veins or that some large lymphatic trunks in the neighbourhood of the receptaculum chyli empty into the rena azygos major. Lippi of Florence in 1825 was the first to maintain that communications between the lymphatic vessels on the one hand and the portal, internal jugular, renal, inferior cava, and azygos veins on the other hand actually existed, but these conclusions were not generally accepted. Recent work would tend, however, to confirm Lippi's contentions. Thus MacAlister ${ }^{1}$ says: "The chief communications of lymphatics with veins are at the junctions of the jugular and subclavian veins on each side, but a few communications of smaller size occur elsewhere, as into the internal iliac and posterior tibial veins."

1 A Text-book of Human Anatomy, p. 89.
Richard Boddaert ${ }^{2}$ experimented on the rabbit, and after ligaturing the thoracic duct and then feeding the animal on a sufficient quantity of fat introduced into the stomach for four hours before its death found that in nearly a third of his experiments (five out of 16) there was a communication between the lymph vessels and the azygos veins. He found moreover, that by applying forceps near the junction of the azygos vein and the right vena cava superior, and exercising pressure on the lumbar lymphatic vessels, with each pressure the azygos vein became distended, while its contents owing to the admixture of lymph then became much paler. Con versely by pressing on the azygos veins the vessels of communication became distended and their contents from

\section{FIG. 1.}

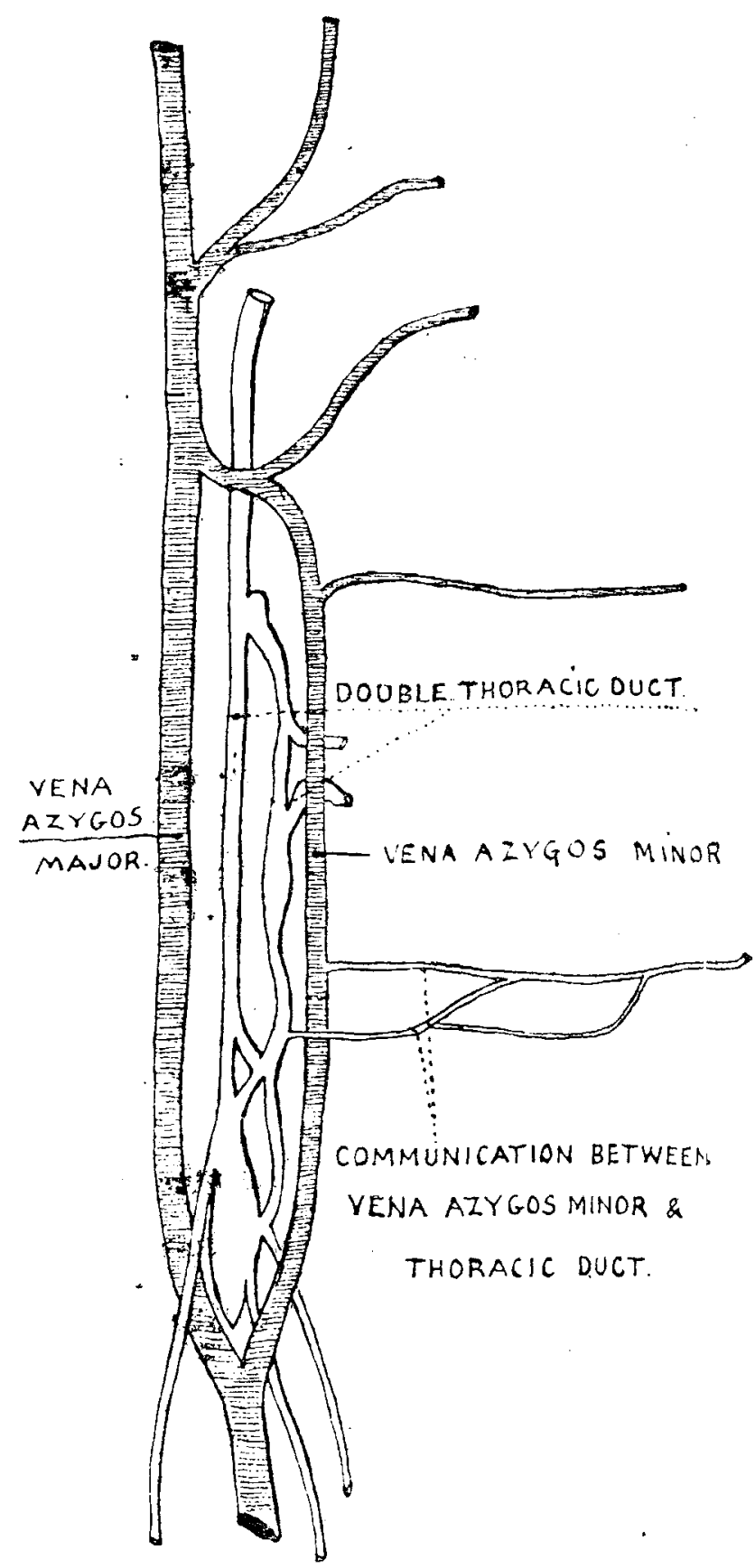

being milky became red. Boddaert has also noticed a large lymphatic trunk pass directly into the external iliac vein. It is always taken for granted that the flow of lymph is from the lymphatic vessel into the vein, and in the great majority of cases, of course, this is the case, but whether it is in. variably so along some of these communicating vessels I think there is good reason to doubt. In Fig. 1, for instance, the blood is obviously passing from the intercostal vein into the rena azygos minor, and from the direction of the communicating vessel probably through this into the left half of the thoracic duct, or, in other words, it would seem, judging by the direction and relative sizes of the vessels, as though the thoracic duct was here receiving a small venous tributary. In the superior mediastinum I have seen small veins coming from the thyroid gland empty themselves directly into the large lymphatic

2 Etude sur une Communication exceptionnelle entre le canal thoracique et la veine azygos chez le lapin. Extrait des Annales de la 
trunks in this region. By some of the smaller veins emptying themselves into the larger lymphatic trunks it would seem that the somewhat sluggish movements of the lymph current would be thereby quickened. Not only are the veins but also small arteries in the thorax brought more immediately into relation with lymphatic vessels than hitherto supposed.

In the specimen from which Fig. 3 was drawn the lymphatic vessels were well marked and at one point, $X, I$ traced from one of them a vessel which at first $I$ took to be a vein. On tracing it further, however, it was proved to be a branch of an intercostal artery. As far as could be seen with the aid of a strong magnifying glass this ressel passed directly at the point $X$ into the lymphatic vessel. In the

F'IG. 2.

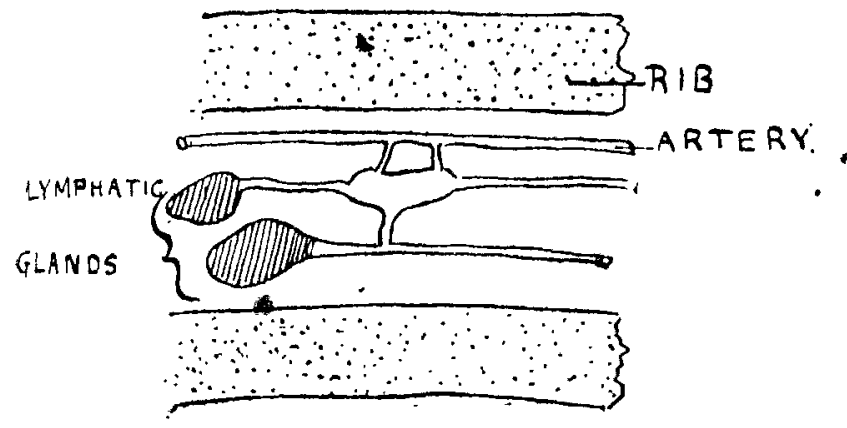

diagram the other terminal branch of the same artery also appeared to end in a lymphatic, but though represented as doing so in the diagram I could not be absolutely certain on the point; however, another branch of the same artery could be easily seen with a magnifying lens to end in a vessel which from the translucency and beaded appearance was obriously lymphatic. Again, in Fig. 2 an intercostal artery is seen to give off two small parallel branches

FIg. ?.

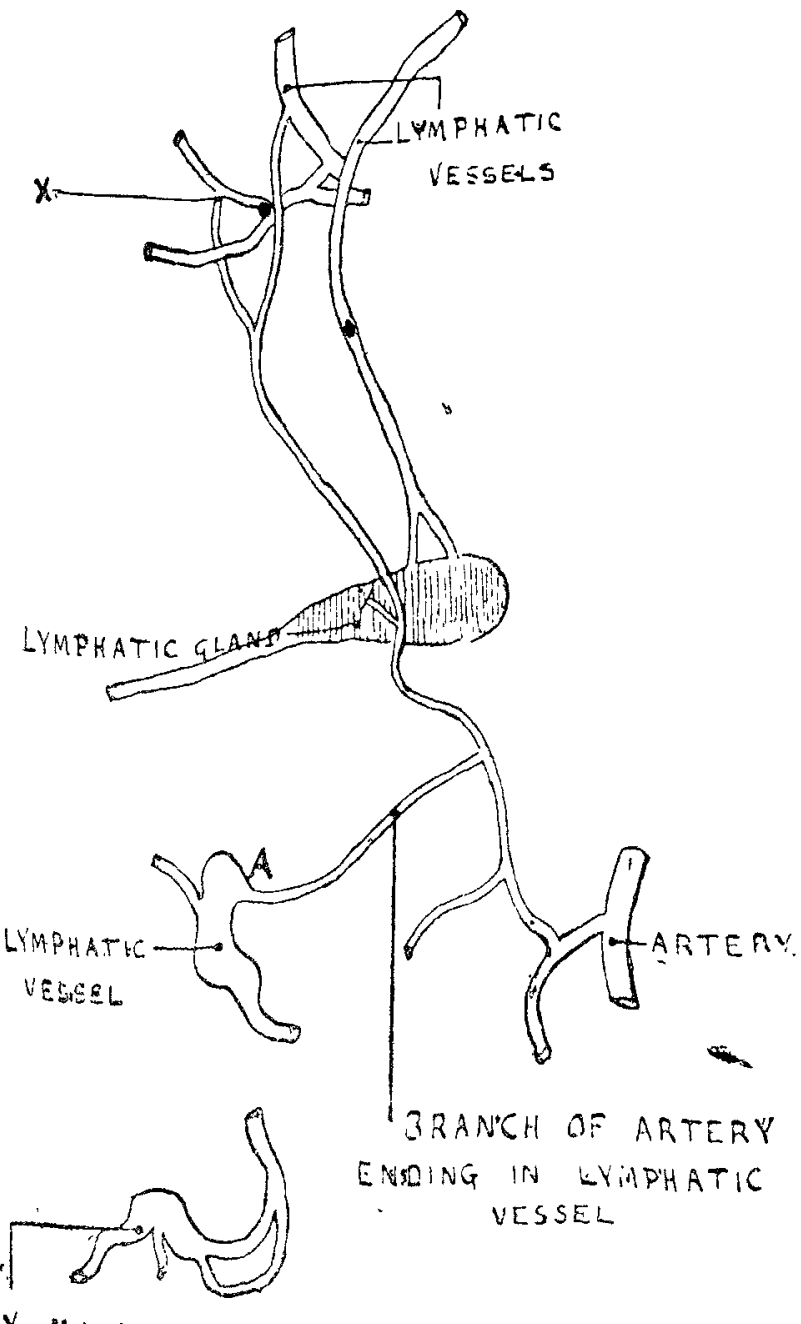

$X$ MAGMIFIED

which end in a dilatation into which a lymphatic vesse passes in at one extremity and emerges at the other; from this dilatation a short branch passes to another lymphatic ressel. In Fig. 4, again, one of the lower intercostal arteries on the right side is seen to give off three branches which unite together and form a loop from the convexity of which a branch passes off which communicates directly with a lymphatic vessel; from this branch, again, another vessel passes off which terminates in the lowest right intercostal vein ; in this case there is a direct communication between

FIG. 4.

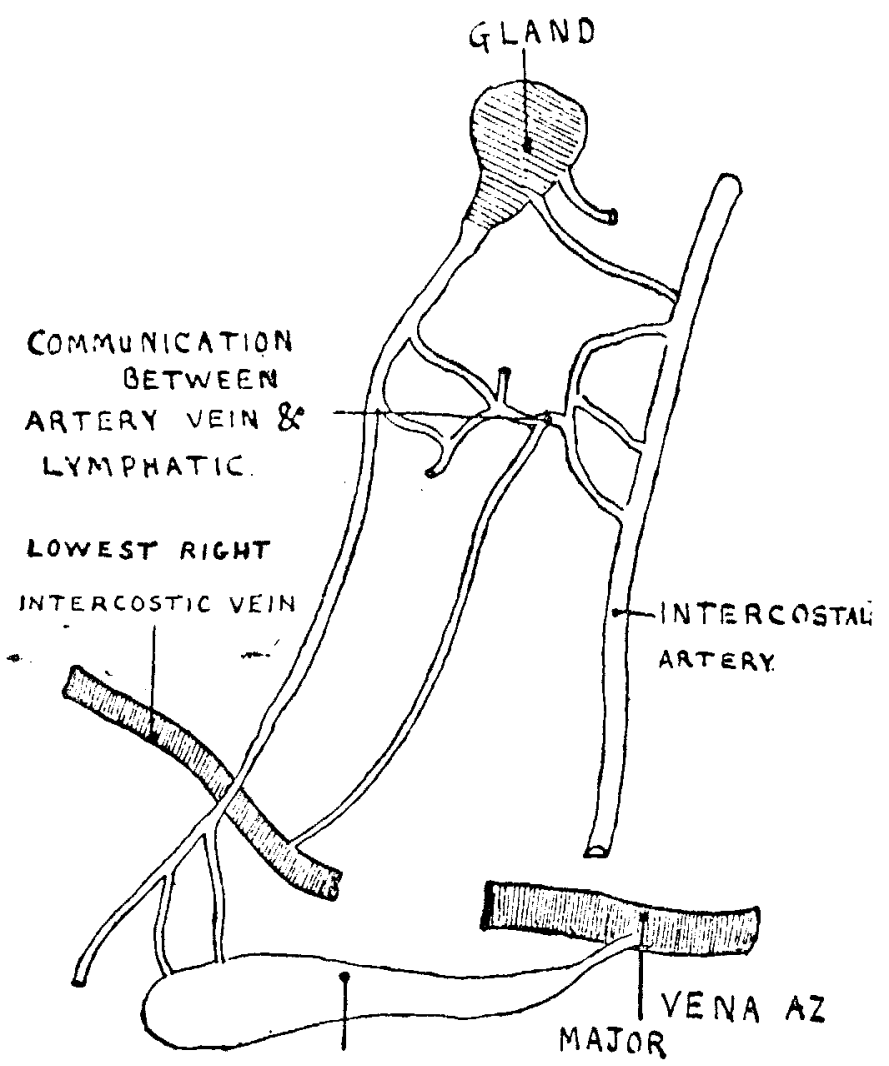

LYMFHATIS DILATATION with libilutary passing into VENA AZYGOS MAJOR.

an artery and a lymphatic vessel and an indirect one with the lowest right intercostal vein.

It has been known for some time that the lymph often assumes a pink or reddish hue, and the colour has been shown ${ }^{3}$ to be due to the presence of red blood corpuscles. How do the corpuscles pass into the lymphatic vessels? If the fact already mentioned is admitted-viz., that a certain number of small arteries pour their contents directly into lymphatic ressels-the presence of these corpuscles is readily explained, and another factor is present which would materially quicken the movements of the lymph; however, it is only right to add that the arteries apparentily do not communicate directly with the lymphatics nearly so frequently as do the veins.

If the communications between the veins and lymphatics can be shown beyond a doubt to take place all over the body - and already they have been observed to exist to a very considerable extent-it follows that we ought to regard the venous system as a part, and that no inconsiderable part, of the absorbent system. We shall then have a ready explanation of certain facts usually regarded as peculiarities in convexion with dissemination of the sarcomata and the carcinomata. It is known that the former usually spread by the veins but sometimes involve the lymphatic glands. The latter invade the lymphatic glands and where secondary deposits are found in the liver, for instance, after carcinoma of the rectum the veins and not the lymphatics are probably the channels through which the cells have passed to reach the liver. It is a fact also that some of the carcinomata, though affecting the lymphatic glands to a slight extent only, yet disseminate rapidly; in such cases it seems hard to believe that the cells have had to traverse innumerable chains of lymphatic glands which, as all admit, act as most efficient barriers before they could pass in to the general circulation. A more ready explanation, I would suggest, and one in accord with the facts, would be that the cells had taken, as it were, a short cut in to the circulation

3 Cyclopadia of Anatomy an 1 Physiology: Lymphatic System by E. Lane, vol. ii ., p. 230. 
either by passing along these communicating vessels into the veins or else had passed into the veins by means of the direct continuity which Frohmann pointed out exists between them and the lymphatic vessels in the substance of the lymphatic gland itself.

In conclusion, then, I would urge the following considerations. 1. The azygos veins normally receive a great many lymphatic vessels. 2. Some of the smaller arteries in the thoracic region open directly into lymphatic vessels; some of the smaller veins open directly into the large lymphatic trunks; and these two factors help to quicken the movements of the lymph. 3. Direct communications are found to exist between arteries, lymphatic vessels, and veins. 4. The communications between veins and lymphatic vessels have been observed to take place in a great many regions in the body. 5. Owing to the presence of these communications the cells of a malignant growth can pass either from the lymphatics into the veins or vice versâ, and hence not only in the sarcomata but also in the carcinomata the veins, as well as the lymphatics, should always be regarded as channels along which the cells may at any moment be conveyed to distant parts of the body.

Wimpole-street, W.

\section{A CONTRIBUTION TO THE SURGERY OF THE KIDNEY.}

BY LEONARD W. BICKLE, F.R.C.S. EDIN., HONORARY SURGEON TO THE ADELAIDE HOSPITAL, SOUTH AUSTRALIA.

THE interest in Case 1 is of a twofold character. First. as another instance of the toleration of the pregnant uterus to abdominal section; and secondly, the smoothness of the case for the first week and then the febrile disturbance due to the recurrence of a dermatitis to which the patient was subject. The dermatitis in this attack was evidently due to the altered excretory conditions, as dermatitis and temperature alike fell when the urine from the remaining kidney reached a normal amount.

CASE 1. Nephrectomy during the third month of pregnanoy : recovery; subsequent normal delivery of a healthy infant at term. -The patient, a married woman, aged 29 years, the mother of four children, was admitted into Adelaide Hospital on March 7th, 1898, complaining of pain and swelling in the left side of two years' duration, which commenced with aching pain in the left side and the lower part of the back. A lump was first noticed about three months previously; the pain had increased much and was of a throbbing, burning character, but was not present every day. At times she passed a very large quantity of urine and then the lump or swelling got larger (?). The patient's father had died in hospital from "swollen knee" and her mother had died from "dropsy" after confinement. The patient had been married 11 years and had had four children. She had had one miscarriage two and a half years previously at about the sixth week. She had lost flesh of late. Her appetite was fairly good but she was unable to take food. Resonance and fremitus were normal. The breath-sounds were harsh and dry. The heart was normal and the arteries were healthy. The skin of the abdomen was flaccid, the lineæ albicantes were well-marked. On the left side a tumour which varied in size was to be felt. The patient had dragging pains when she tried to lie on the right side, but none when lying on the left side. The tumour was not to be differentiated from the left lobe of the liver. It was situated under the left costal arch, and though it was not moveable yet it came down with respiration. It measured about four and a half inches vertically and four inches transversely, it was not painful to touch, and was apparently cystic in character. The urine was of specific gravity 1020 ; it was clear, acid, and contained no sugar or albumin. The skin was very harsh and dry and was usually so, especially in winter. On March 14th the patient complained of much pain. On the 15th the urine was turbid and contained a small amount of pus and albumin. The urine had been measured daily so far, but had not varied much in amount. On the 17th a consultation was held; further observation was advised before operating. On the 27 th the tumour had increased in size and could be pushed into the loin; the patient's distress was greater. On the 29th, in view of the increasing size of the tumour and pain and the probability of the patient being pregnant, in further consultation a laparotomy was agreed upon and carried out forthwith. Chloroform was given by Dr. Kinınont. I started my incision from the costal arch at the linea semilunaris and continued it somewhat down and out for two and a half inches. On the abdomen being opened the cyst was found to be retroperitoneal. The incision was extended about one inch. The posterior layer of the peritoneum was cut through and the cyst was exposed. The cyst was tapped and a small amount of clear fluid with a faint urinous smell was drawn off. Whilst this was being tested the cyst suddenly ruptured. The fact that the cyst contained no mother or daughter cyst negatived a possible origin-viz., hydatid of the kidney. The thin walls of the cyst and the ready rupturing showed what would have happened later if the tumour had been left and the pregnancy had progressed. Having thos a hydronephrosis to deal with it was decided to remove the cyst and kidney rather than to leave a permanent urinary fistula. Accordingly the kidney was brought out and the pedicle was transfixed with a blunt needle and tied with a Staffordshire knot. The vessels and the ureter were re-tied on the face of the stump. No other vessels required tying during the whole operation. The abdomen was then flushed out with woric solution and the wound was closed with silkworm-gut sutures, a glass drainage-tube with a rubber drain being left in the lower part. The upper part of the wound was sealed with Whitehead's paint. The temperature after the operation was $96.8^{\circ} \mathrm{F}$. The afternoon temperature of reaction was $101^{\circ}$. There was no sickness for over 12 hours. A small amount of fluid was drawn off." On the 30th sickness and flatulence were a little troublesome and the temperature was $99.2^{\circ}$. The drainage-tube was removed and the stitch which had been left loose was tied. Three grains of subchloride of mercury were given and one ounce of haustus albus in the morning. The urine measured $8+6$ ounces. On the 31 st there was less sickness. The urine measured $8+9$ ounces= 17 ounces. On April 4th the patient's condition was good, all going well. The wound when dressed was found to be quite healed. On the 7 th the patient was not quite so well, complaining of pain in the left side; the temperature was $100^{\circ}$. On the 8th her general condition was about the same; there was some exudation about the stump. On the 10th she was better; ber skin was harsh and dry, and there was some dermatitis. On the 12th she had pains in nearly all of her joints and the dermatitis was very troublesome, preventing sleep. The temperature was $98.4^{\circ}$ in the morning and 100.4 in the evening. Sodium salicylate and sodium bicarbonate were given. On the 16 th the temperature was $984^{\circ}$ in the morning and $103^{\circ}$ in the evening. On the 18th the temperature was $99^{\circ}$ in the morning and $102.4^{\circ}$ in the evening; there was much irritation; the urine measured 21 ounces. The patient was sleepless. It was probable that the whole irritation and trouble were due to want of compensation by the right kidney. One-twentieth of a grain of pilocarpine was given every four hours. On the 19th the temperature was $98^{\circ}$ in the morning and $100.6^{\circ}$ in the evening. On the 20th the urine measured 43 ounces; the dermatitis was almost gone. The cicatrix was firm and sound. The temperature was $984^{\circ}$ in the morning and $99.4^{\circ}$ in the evening. The uterine enlargement steadily increased. There was no further trouble.

In due course the patient was delivered of a healthy child, the labour being normal in every way. She came to see $m$ some weeks later to show her child who was the picture of health. There was no vestige of ventral hernia. In August, 1899, I heard that the patient was quite well.

CASE 2. Nephro-lithotomy.-The patient was a man, 56 years of age, who first consulted me in September, 1891 complaining of pain in his left side of over 12 years dura tion. In the earliest onset once or twice he had passed blcod in his urine, but none since. The pain was aggravated by exertion and at times it was severe. He also complained of localised aweating. This was curiously marked. The unde vest would be quite wet for an inch or two in width round the zone of this pain which was that of the left renal region. The sweating was a great source of discomfort. I have noticed the same localised sweating since then in kidney cases. The urine was clear and pale, giving just a faint ring of albumin with cold nitric acid. Microscopically a fer blood corpuscles, leucocytes, and crystals of oxalate of lime were seen. The diagnosis arrived 